OPEN ACCESS

Edited by:

Roberto Paganelli,

University of Studies G. d'Annunzio

Chieti and Pescara, Italy

Reviewed by:

Michinori Toriyama,

Kwansei Gakuin University, Japan

Bashir M. Rezk,

Southern University at New Orleans,

United States

*Correspondence:

Ricardo Espinosa-Tanguma espinosr@uas/p.mx

Specialty section:

This article was submitted to Experimental Pharmacology

and Drug Discovery,

a section of the journal

Frontiers in Pharmacology

Received: 05 May 2020

Accepted: 30 June 2020

Published: 16 July 2020

Citation:

Acosta-Elias $J$ and Espinosa-Tanguma $R$ (2020) The Folate Concentration and/or Folic Acid

Metabolites in Plasma as Factor

for COVID-19 Infection.

Front. Pharmacol. 11:1062. doi: 10.3389/fphar.2020.01062

\section{The Folate Concentration and/or Folic Acid Metabolites in Plasma as Factor for COVID-19 Infection}

\author{
Jesus Acosta-Elias ${ }^{1}$ and Ricardo Espinosa-Tanguma ${ }^{2 *}$ \\ ${ }^{1}$ Facultad de Ciencias, Universidad Autónoma de San Luis Potosí, San Luis Potosí, Mexico, 2 Facultad de Medicina, \\ Universidad Autónoma de San Luis Potosí, San Luis Potosí, Mexico
}

Pregnant women appear to be more susceptible to infectious diseases than women in reproductive age. According to the California Department of Public Health pregnant women were 9.6-folds more likely to be hospitalized during the 2009 influenza outbreak when compared to non-pregnant women in reproductive age. In contrast, it was reported that of 16,749 COVID-19 patients that were hospitalized in the UK, the probability for pregnant women to require in-patient care due to infection by SARS-CoV-2 was 0.95 versus non-pregnant women. Therefore $9.6 / 0.95=10.10$, which brings us to the conclusion that pregnant women are 10.10-folds less likely to be hospitalized for a SARS-CoV-2 infection than for the $2009 \mathrm{H} 1 \mathrm{~N} 1$ pandemic. Folic acid supplementation during pregnancy could be the factor that is protecting these patients against SARSCoV-2 infection. Two independent papers that used informatic simulation proved that folic acid reduced the replication of this virus. One of them showed that folic acid inhibits the furin protease which the virus needs in order to enter its host cell, while the other one explained that folic acid inactivates protease $3 \mathrm{CL}^{\text {pro }}$, a protein that the virus needs to replicate. Nonetheless the probability that folic acid blocks two different proteins is very low, therefore the mechanism by which folic acid has apparently protected pregnant women during the COVID-19 pandemic has not been determined.

Keywords: SARS-CoV-2, folic acid, furin, viral infection, ace2

\section{INTRODUCTION}

SARS-CoV-2 virus has caused a worldwide pandemic that is expanding, originating a serious public health crisis. Thus far a treatment has not been found and some countries have encountered a 7\% death rate. Because of this high percentage, a vaccine is of the outmost importance but it is a year and a half away from being available for public use, this calls for the use of other medications that reduce the likelihood of presenting symptoms and are capable of slowing down the spread of the virus around the globe. 


\section{FOLIC ACID}

Folate is a hydro-soluble vitamin that classifies as part of the vitamin B complex. It is widely found in nature and a wellbalanced diet provides the required daily needs for a healthy person. Many populations around the world have a diet that consists of crops such as potatoes, corn and rice on a daily basis, which are known to have a low folate concentration, originating a high deficiency prevalence (Gorelova et al., 2017). It is well known that folate intake is essential for human health because it prevents megaloblastic anemia and neural tube birth defects as well as cardiovascular disease, dementia, cognitive function alterations, osteoporosis and several types of cancer.

The food and Drug Administration (FDA) in the USA issued a regulation in 1996 requiring for all grain products to contain 140 mcg of folic acid (FA) per $100 \mathrm{~g}$ (Jacques et al., 1999), aiming to reduce the likelihood of new-born babies suffering from neural tube defects.

FA is a synthetic form of folate that is rarely found in nature. In order to process it into the organism after it is absorbed in the intestine (which is a very efficient process) it first needs to be reduced into dihydrofolate (DHF) and posteriorly into its active form tetrahydrofolate (THF) (Ducker and Rabinowitz, 2017).

Aside from diet, folate availability in humans is genetically modulated. There are several known polymorphisms of genes that codify for folate metabolizing enzymes, including $677 \mathrm{C} \rightarrow \mathrm{T}$ and the 1298A3C alleles of 5,10 methylene-THF reductase (MTHFR (MIM 607093)) among them (Yang et al., 2008).

The genetic alteration in $677 \mathrm{C} \rightarrow \mathrm{T}$ causes a thermolabile MTHFR enzyme with a diminished capacity to catalyze the conversion of 5,10-methylene-THF to 5-methyl-THF, a necessary step to obtain methionine from homocysteine. The presence of $677 \mathrm{C} \rightarrow \mathrm{T}$ is related to occlusive vascular disease (Amaral et al., 2017), neural tube defects (Zhang et al., 2019), Alzheimer's disease (Rai, 2017) and hypertension (Shen et al., 2016).

Plasma and red blood cell (RBC) concentration also depends on the person's ethnical group. For example, Non-Hispanic whites possess a $1,180 \mathrm{nmol} / \mathrm{L} \mathrm{RBC}$ concentration in contrast to Non-Hispanic African Americans who have a $906 \mathrm{nmol} / \mathrm{L}$ (Pfeiffer et al., 2019). On the other hand, pregnant women who were taking $400 \mathrm{mcg}$ of FA per day can reach a concentration of 2,862 $\mathrm{nmol} / \mathrm{L}$ in RBC at delivery (Plumptre et al., 2015).

\section{HOSPITALIZED PREGNANT WOMEN DURING 2009 A-H1N1 PANDEMIC}

Pregnant women appear to be more susceptible to infectious diseases than women in reproductive age (Sappenfield et al., 2013). For example, during the 2009 influenza A-H1N1 pandemic the California Department of Public Health (CDPH) reported 94 pregnant women and 137 non-pregnant women who were in reproductive age that required in-patient care for Influenza H1N1 infection from April 23rd to August 11th, 2009 (Louie et al., 2010). The birth rate per 1,000 women in reproductive age in the USA during that year was 66.7 (Martin et al., 2011). Hence, for every 66.7 pregnant women there were
933.3 non-pregnant women in reproductive age. The probability that a pregnant woman will be hospitalized is obtained by means of the conditional probability equation: $P(A / E)=\frac{P(A \cap E)}{P(E)}$ where event $\mathrm{A}=$ hospitalization and event $\mathrm{E}=$ pregnant women. Substituting values we obtain $P(A / E)=94 / 66.7=1.40929$ (this result is not to be interpreted, it is merely a ratio). For the women in reproductive age and not pregnant $P(A / N E)=$ $\frac{P(A \cap N E)}{P(N E)}$, where event $\mathrm{A}=$ hospitalization and event $\mathrm{NE}=$ nonpregnant women. Substituting values $P(A / N E)=137 / 933.3=$ 0.14679 . Therefore the probability for a pregnant woman to require being hospitalized when compared to a non-pregnant woman who is in reproductive age is $1.40929 / 0.14679=9.6$. In other words, pregnant women were 9.6-folds more likely to be hospitalized for influenza H1N1 in 2009 than non-pregnant women in reproductive age.

\section{HOSPITALIZED PREGNANT WOMEN DURING THE COVID-19 PANDEMIC}

According to the UK's Office for National Statistics, the number women in reproductive age (15-45 years) by mid 2019 was $12,932,446$ (Park, 2019) and the number of births in 2018 was 731,213 (Campbell, 2018). When this paper was written, there was no data regarding births in 2019. Extrapolating (731,213/ $(12,932,446-731,213))^{\star} 1,000$, the birth rate per 1,000 women in reproductive age was 59.929 , thus it can be assumed that out of 59.929 pregnant women in the UK there are 940.071 nonpregnant women in reproductive age.

Docherty et al. (2020) reported that between February 6th 2PM and April 18th 2PM hospitals in England, Scotland and Wales admitted a total of 16,749 patients with COVID-19, 908 of those patients were non-pregnant women in reproductive age and 55 were pregnant women. The probability for a pregnant woman to be hospitalized is obtained by using again the conditional probability equation: $55 / 59.929=0.9177$, whereas the probability for a non-pregnant woman to require in patient care is $908 / 940.071=0.9659$. The probability for a pregnant women to be hospitalized when compared to a non-pregnant woman in reproductive age is $0.9177 / 0.9659=0.95$.

In a study conducted at the New York Presbyterian Allen Hospital and Columbia University Irving Medical Center between March 22nd and April 4th 2020, analyzed 216 pregnant women who delivered infants and were tested for SARS-CoV-2 obtaining the following data: $84.6 \%$ were negative, $13.5 \%$ were asymptomatic and positive and only $1.9 \%$ were positive and symptomatic (Sutton et al., 2020).

\section{HOSPITALIZED PREGNANT WOMEN DURING THE COVID-19 PANDEMIC VS 2009 A-H1N1 PANDEMIC}

Pregnant women are more susceptible to different infections, but in the case of SARS-CoV-2 they appear to be protected. If we compare with the $2009 \mathrm{H} 1 \mathrm{~N} 1$ pandemic we can see that the magnitude of this protection is $9.6 / 0.95=10.10$. Furthermore, during the H1N1 
pandemic no ethnic differences were reported among pregnant patients who required being hospitalized (Louie et al., 2010).

Knight et al. (2010) reported that out of all pregnant women that were hospitalized in the UK between March 1st and April 14th 2020 due to an infection by SARS-CoV-2, 56\% were black women or belonged to other ethnic minorities. The estimated incidence per 1,000 maternities of admission with SARS-CoV-2 infection was 28.4 for black women and 3.5 for white women. Therefore the black pregnant women are 8 folds (28.4/3.5) more likely to require in-patient care when compared to white pregnant women.

By June 13 of this year, Black Americans represent 12.4\% of the population in the U.S., but they have suffered $24.3 \%$ of known COVID-19 deaths (Egbert et al., 2020). Using conditional probability equation, it can be estimated that Black Americans have a 2.27 -folds more probability of dying from this infection than the rest of the ethnic groups in the U.S.

Thus, there is a possibility that FA supplementation in pregnant women confers them a protection that diminishes the likelihood of requiring hospitalization for SARS-CoV-2 infection by 10 -fold when compared to the need for in-patient care during de $2009 \mathrm{H} 1 \mathrm{~N} 1$ pandemic.

It may be that pregnant women who get infected abandoned their FA supplementation or did not take it as prescribed. Kinnunen et al. (2017) reported that during pregnancy, supplement use of FA was most common in European women (65.7\%) and least common in Middle Eastern (29.4\%) and African women (29.0\%). There is also the possibility that some patients possess a polymorphism that alters their folate metabolism which places them at a higher risk for getting infected with SARS-CoV-2 as well as an increased probability of being symptomatic or requiring in-patient care.

\section{DISCUSSION}

On this paper we presented evidence that suggests that pregnant women possess a protective factor that decreases their chance of being hospitalized due to a SARS-CoV-2 infection by ten folds compared to the data obtained during the $2009 \mathrm{H} 1 \mathrm{~N} 1$ pandemic. We propose their FA intake during pregnancy as the likely protective factor, however the means by which this is accomplished is still unclear. There are two independent works that have shown by computer simulation that FA can reduce the replication of this virus. In one of them (Sheybani et al., 2020) have shown that FA can inactivate the furin (Braun and Sauter, 2019)

\section{REFERENCES}

Amaral, F., Miranda-Vilela, A., Lordelo, G., Ribeiro, I., Daldegan, M., and Grisolia, C. (2017). Interactions among methylenetetrahydrofolate reductase (mthfr) and cystathionine $\beta$-synthase (cbs) polymorphisms - a cross-sectional study: multiple heterozygosis as a risk factor for higher homocysteine levels and vaso-occlusive episodes. Genet. Mol. Res. 16 (1), 1-9. doi: $10.4238 /$ gmr16019374

Braun, E., and Sauter, D. (2019). Furin-mediated protein processing in infectious diseases and cancer. Clin. Trans. Immunol. 8, e1073. doi: 10.1002/cti2.1073 endoprotease. This endoprotease is crucial for the SARS-CoV-2 virus to enter its host cell (Coutard et al., 2020; Hua et al., 2020). While the other one (Serseg et al., 2020) explained that FA inactivates protease $3 \mathrm{CL}^{\text {pro }}$, which is vital in the replication of all coronaviruses (Min-Feng et al., 2005). The virus that originated the 2009 H1N1 pandemic did not need a furin endoprotease or a $3 \mathrm{CL}^{\text {pro }}$ protease in order to replicate (Fujioka et al., 2018), however it seems very unlikely that FA could inhibit two different proteases. FA's half-life is approximately $1.53 \pm 0.46 \mathrm{~h}$ (Loew et al., 1987), although in the $10 \mathrm{~h}$ following its administration it could still be detected in small concentrations in plasma. It may be that SARSCoV-2 virus inactivation is through THF molecules. With a 400 mcg FA supplementation per day pregnant women may reach concentrations as high as $2,323 \mathrm{nmol} / \mathrm{L}$ in $\mathrm{RBC}$ and $52 \mathrm{nmol} / \mathrm{L}$ in plasma at 12-16-week gestation (Plumptre et al., 2015). If this were the case, the severity of the infections may be inversely proportional to the concentration of certain folate molecules in the body. In other words, the mechanism by which FA supplementation protects pregnant women against SARS-CoV-2 is uncertain.

\section{CONCLUSIONS}

Certain evidence seems to suggest that FA suplementation could be a protector against infection by SARS-CoV-2. Pregnant women seem to have a lower probability of acquiring this infection and those who are infected have a higher chance of being asymptomatic. On the contrary, pregnant women of ethnic groups who have a low folate RBC concentration secondary to genetic characteristics and/or does not receive FA supplementation have a higher hospitalization rate. This evidence shows that FA supplementation may protect against SARS-CoV-2.

\section{AUTHOR CONTRIBUTIONS}

All the authors have contributed equally to the development of this work.

\section{FUNDING}

This work was partially supported by the Universidad Autónoma de San Luis Potosí. 
Ducker, G. S., and Rabinowitz, J. D. (2017). One-carbon metabolism in health and disease. Cell Metab. 25 (1), 27-42. doi: 10.1016/j.cmet.2016.08.009

Egbert, A., Clary, B., Helmstetter, C., and Cortes, G. (2020). The color of coronavirus: Covid-19 deaths by race and ethnicity in the u.s. (APM Research Lab).

Fujioka, Y., Nishide, S., Ose, T., Suzuki, T., Kato, I., Fukuhara, H., et al. (2018). A sialylated voltage-dependent $\mathrm{Ca}^{2+}$ channel binds hemagglutinin and mediates influenza a virus entry into mammalian cells. Cell Host Microbe 23 (6), 809818. doi: 10.1016/j.chom.2018.04.015

Gorelova, V., Ambach, L., Rébeillé, F., Stove, C., and Van Der Straeten, D. (2017). Folates in plants: Research advances and progress in crop biofortification. Front. Chem. 5, 21. doi: 10.3389/fchem.2017.00021

Hua, L., Wu, C., Yang, Y., Liu, Y., Zhang, P., Wang, Y., et al. (2020). Furin, a potential therapeutic target for covid-19. Chinaxiv.

Jacques, P. F., Selhub, J., Bostom, A. G., Wilson, P. W., and Rosenberg, I. H. (1999). The effect of folic acid fortification on plasma folate and total homocysteine concentrations. New Engl. J. Med. 340 (19), 1449-1454. doi: 10.1056/ NEJM199905133401901

Kinnunen, T. I., Sletner, L., Sommer, C., Post, M. C., and Jenum, A. K. (2017). Ethnic differences in folic acid supplement use in a population-based cohort of pregnant women in norway. BMC Pregnancy Childbirth 17 (143), 1-9. doi: $10.1186 / s 12884-017-1292-\mathrm{x}$

Knight, M., Bunch, K., Vousden, N., Morris, E., Simpson, N., Gale, C., et al. (2020). Characteristics and outcomes of pregnant women admitted to hospital with confirmed sars-cov-2 infection in uk: national population based cohort study. BMJ 369. doi: 10.1136/bmj.m 2107

Loew, D., Eberhardt, A., Heseker, H., and Kubler, W. (1987). Zur plasmakinetik und elimination von folsaure. Klin. Wochenschrift 65 (11), 520-524. doi: 10.1007/BF01721039

Louie, J. K., Acosta, M., Jamieson, D. J., and Honein, M. A. (2010). Severe 2009 h1n1 influenza in pregnant and postpartum women in california. N. Engl. J. Med. 362, 27-35. doi: 10.1056/NEJMoa0910444

Martin, J. A., Hamilton, B. E., Ventura, S. J., Osterman, M. J., Kirmeyer, S., Mathews, T., et al. (2011). Births: final data for 2009. Natl. Vital Stat. Rep. 60 (1), 1-70.

Min-Feng, H., Chih-Jung, K., Kai-Ti, C., Hui-Chuan, C., Chia-Cheng, C., TzuPing, K., et al. (2005). Mechanism of the maturation process of sars-cov $3 \mathrm{cl}$ protease. J. Biol. Chem. 280 (35), 31257-31266. doi: 10.1074/jbc.M502577200

Park, N. (2019). Estimates of the population for the uk, england and wales, scotland and northern ireland. (Office for National Statistics).

Pfeiffer, C. M., Sternberg, M. R., Zhang, M., Fazili, Z., Storandt, R. J., Crider, K. S., et al. (2019). Folate status in the us population $20 \mathrm{y}$ after the introduction of folic acid fortification. Am. J. Clin. Nutr. 110, 1088-1097. doi: 10.1093/ajcn/nqz184

Plumptre, L., Masih, S. P., Ly, A., Aufreiter, S., Sohn, K.-J., Croxford, R., et al. (2015). High concentrations of folate and unmetabolized folic acid in a cohort of pregnant Canadian women and umbilical cord blood. Am. J. Clin. Nutr. 102, 848-857. doi: 10.3945/ajcn.115.110783

Rai, V. (2017). Methylenetetrahydrofolate reductase (mthfr) $\mathrm{c} 677 \mathrm{t}$ polymorphism and alzheimer disease risk: a meta-analysis. Mol. Neurobiol. 54 (2), 1173-1186. doi: 10.1007/s12035-016-9722-8

Sappenfield, E., Jamieson, D. J., and Kourtis, A. P. (2013). Pregnancy and susceptibility to infectious diseases. Infect. Dis. Obstet. Gynecol. 2013, 1-8. doi: $10.1155 / 2013 / 752852$

Serseg, T., Benarous, K., and Yousfi, M. (2020). Hispidin and lepidine e: Two natural compounds and folic acid as potential inhibitors of 2019-novel coronavirus main protease, (2019- ncovmpro), molecular docking and sar study. Curr. Computer-Aided Drug Des. 16, 1-11. doi: 10.2174/157340991666 6200422075440

Shen, M., Tan, H., Zhou, S., Retnakaran, R., Smith, G. N., Davidge, S. T., et al. (2016). Serum folate shows an inverse association with blood pressure in a cohort of chinese women of childbearing age: A cross-sectional study. PloS One 11 (5), 1-9. doi: 10.1371/journal.pone.0155801

Sheybani, Z., Dokoohaki, M. H., Negahdaripour, M., Dehdashti, M., Zolghadr, H., Moghadami, M., et al. (2020). The role of folic acid in the management of respiratory disease caused by covid-19. ChemRxiv. 1-15. doi: 10.26434/ chemrxiv.12034980.v1

Sutton, D., Fuchs, K., D’Alton, M., and Goffman, D. (2020). Universal screening for sars-cov-2 in women admitted for deliver. N. Engl. J. Med. doi: 10.1056/ NEJMc2009316

Yang, Q.-H., Botto, L. D., Gallagher, M., Friedman, J., Sanders, C. L., Koontz, D., et al. (2008). Prevalence and effects of gene-gene and gene-nutrient interactions on serum folate and serum total homocysteine concentrations in the United States: findings from the third National Health and Nutrition Examination Survey DNA Bank. Am. J. Clin. Nutr. 88, 232-246. doi: 10.1093/ajcn/88.1.232

Zhang, Y., He, X., Xiong, X., Chuan, J., Zhong, L., Chen, G., et al. (2019). The association between maternal methylenetetrahydrofolate reductase c677t and a1298c polymorphism and birth defects and adverse pregnancy outcomes. Prenat. Diagn. 39 (1), 3-9. doi: 10.1002/pd.5396

Conflict of Interest: The authors declare that the research was conducted in the absence of any commercial or financial relationships that could be construed as a potential conflict of interest.

Copyright $\odot 2020$ Acosta-Elias and Espinosa-Tanguma. This is an open-access article distributed under the terms of the Creative Commons Attribution License (CC BY). The use, distribution or reproduction in other forums is permitted, provided the original author(s) and the copyright owner(s) are credited and that the original publication in this journal is cited, in accordance with accepted academic practice. No use, distribution or reproduction is permitted which does not comply with these terms. 